\title{
An Information Theory-Based Framework for Development of the Human-Centered System Sustainability Index
}

\author{
Waldemar Karwowski ${ }^{1 *}$ and Tareq Z. Ahram ${ }^{1}$ \\ ${ }^{1}$ University of Central Florida, Department of Industrial Engineering \& Management Systems, Institute for Advanced Systems Engineering 12800 Pe- \\ gasus Drive, Orlando, Florida 32816
}

\begin{abstract}
This paper discusses the development of a conceptual framework for assessing the human-centered system sustainability at the economic, environmental and societal levels. An individual component sustainability measure is defined as the degree to which a specific sustainability criterion has been met. The quantification framework for such an assessment is defined in an analogous way to the notion of system compatibility based on information theory. The above approach is at the center of current research efforts, which aim to quantify the progress towards achieving sustainability at the national arena. The proposed human-centered sustainability framework, as well as the corresponding concept of the global sustainability index (GSI), should help in the quest of building sustainable working and living environments of the future.
\end{abstract}

Keywords: human-centered design; system sustainability; society, economics; environment; information theory; system compatibility; sustainability measure; global sustainability index.

\section{Introduction}

Sustainability, as a concept appears in many different contexts, including sustainable development, and is generally related to our ability to sustain natural resources for future generations (Brundtland, 1987; Adams and Jeanrenaud, 2008). The United Nations Millennium Declaration (2005) identified principles of sustainable development, including economic development, environmental protection, and social development. For example, social sustainability dimensions calls for a decent standard of living without compromising the needs of future generations. In this context, while protecting the environment, the economic and social sustainability efforts should focus on the following (United Nations, 2015):

- Helping people overcome poverty and secure good jobs,

- Providing access to clean energy, and assuring that the energy production does not contribute to climate change.

- Making sure that everyone can get the water, food and nutrition they need.

- Designing the urban areas so that citizens can enjoy a decent quality of life.

- Building transportation systems that prevent traffic congestion and air pollution.

- Assuring that the oceans are healthy and that marine life is not threatened by pollution and climate change.

- Assuring that communities are resilient in the face of natural disasters.

As predicted by the United Nations (2015), the world population will likely to increase from seven billion today to reach nine billion by the year 2050. At the same 
time, greenhouse gas emissions will continue to rise, while access to clean water and availability of energy resources will remain limited. According to the National Academy of Engineering (2009), "as the population grows and its needs and desires expand, the problem of sustaining civilization's, continuing advancement, while still improving the quality of life, looms more immediate."Sustainability promotes the development of environmentally responsible and socially relevant, innovative, smart, and efficient workplaces, businesses, communities, and societies.

From the above perspective, the application of human factors and ergonomics (HFE) and systems thinking to global sustainability efforts can provide an unparalleled opportunity for the integration of economic, societal, environmental, and above all, human-centered approaches, considerations, and strategies. The application of HFE to assure the highest levels of human-systems integration at all levels of society promotes human safety, health and well-being, while maximizing business value, and optimally utilizing earth's valuable resources. A comprehensive approach to sustainability, which should be considered from a global socioeconomic perspective, cannot be successful without the involvement of all stakeholders. The social responsibility is reflected by the humancentered design focus in the decision-making processes that occur at the individual, organization, community, and societal levels.

\section{Human Factors and Sustainability}

The philosophy and guiding principles of HFE can be applied to steer the development of comprehensive sustainability plans that aim to support prosperous, healthy and livable communities and societies for current and future generations. According to the United Nations (UN) and the Sustainable Development Goals (SDGs) identified in Rio+20 (UNCSD, 2012), an effective sustainability plan can be achieved by addressing economic, environmental, social and cultural needs in a holistic and comprehensive manner. Addressing current and future sustainability challenges can be accomplished by implementing a comprehensive and robust approach that encompasses the human-centered approach, human-systems integration, and systems engineering methodologies. Such approach should start with a needs assessment, the identification and development of goals, a system requirements analysis, the design of strategies and metrics to measure progress, the implementation of a plan with specific assignments, and the determination of resources needed and an appropriate timeline. The approach should end with the evaluation of results and assessment of the progress made with respect to present and future sustainability needs. From this perspective, human-systems thinking is at the core of any sustainability approach; it supports creating a shared understanding of longterm goals and establishing strategic priorities, while constantly identifying and communicating human needs, visions, goals and strategies. This paper focuses on the broader spectrum of societal sustainability needs, while illustrating how HFE, human-systems integration, and systems engineering disciplines can play a crucial role in achieving the goals of effective sustainability efforts worldwide.

The International Ergonomics Association (IEA 2003) defined human factors and ergonomics (HFE) as "the scientific discipline concerned with the understanding of the interactions among humans and other elements of a system, and the profession that applies theory, principles, data, and methods to design in order to optimize human well-being and overall system performance." According to Karwowski (2005), HFE is a unique and independent discipline and profession; it is one that focuses on the nature of human-technology interactions from the unified perspective of science, engineering, design, and management of human-centered systems applied to a wide variety of natural and artificial products, processes, and living environments. Human factors practitioners contribute to the design and evaluation of products, environments, and ecological systems to ensure their compatibility with human abilities and limitations and, above all, the general community and workplace sustainability needs.

Given the unparalleled global changes and technological developments in our recent history, one must wonder if the current HFE philosophy is sufficient and adequate to address the everincreasing sustainability challenges. For example, the Human Factors and Ergonomics Society aims to "advocate systematic use of HFE knowledge to achieve compatibility in the design of interactive 
systems of people, machines, and environments... to ensure their effectiveness, safety, and ease of performance" (HFES, 2015). However, is the "effectiveness, safety, and ease of performance" all that HFE can contribute in this context? Are we fulfilling the above mission when applying human-centered principles in the quest to design and produce cars that are effective, safe and easy to operate, but consume a lot of gasoline? Are we fulfilling the above mission when applying humancentered principles in the quest to design and build power plants that are effective, safe and easy to operate- generating energy by burning fossil fuels, but also releasing a great amount of $\mathrm{CO}_{2}$ into the atmosphere, leaving a significant carbon footprint on earth? Are we fulfilling the above mission when applying human-centered principles in the quest to design industrial food production facilities that are effective, safe and easy to operate, but utilize extraordinarily high water-intensive practices? It takes, for example, between 500 and 1,500 liters of water, on average, to produce 1 kilogram of potatoes, and between 15,000 and 70,000 liters of water, on average, to produce 1 kilogram of beef. At the same time, millions of people around the world, especially in Africa, do not have direct access to clean and drinkable water. As pointed out by NAE (2009), "a world divided by wealth and poverty, health and sickness, food and hunger, cannot long remain a stable place for civilization to thrive."

In view of the above, one needs to ask the question of how the HFE discipline and profession can better serve the global society at large, and what aspirations of and opportunities for HFE exist to contribute in this regard (Moray, 1995)? Are the problems of sustainable environments, hunger and malnutrition, greenhouse gases emission, energy and clean water supply, and security for the entire human population on this earth important enough for us to consider refocusing the current HFE approach? Clearly, HFE cannot be indifferent to a greater socio-economic and political context in which to advocate the benefits of the theory and the practice of human-centered design.

Furthermore, HFE cannot just focus on the application of a user-centered philosophy to the socially, economically, and environmentally unsustainable systems to make them compatible with humans. The main challenge that needs to be addressed by the HFE community in the 21st century is how HFE can contribute in a meaningful and significant way to the development of sustainable complex systems-of-systems, including products, processes, technologies, working and living environments, ecosystems, entire communities, and nations around the world (Karwowski, 2007).

\section{Human-Centered Design and Sustainability}

The human factors and ergonomics discipline has been continually evolving over the last 60+ years as a holistic approach to the design of human-compatible systems (Wilson and Corlett, 1990; Sanders and McCormick, 1993; Chapanis, 1999; Salvendy, 1997; Vicente, 2004; Stanton et al., 2004; Karwowski, 2005). The future humancentered philosophy and design for sustainability should focus on the systematic use of HFE knowledge to achieve compatibility in the design of environmentally, economically and socially sustainable interactive systems of people and technology. HFE can contribute to comprehensive and effective sustainability efforts, which are founded on the principles of human-centered design, to provide the basis from which sustainable world can be achieved. A generic framework for such a human-centered design approach to sustainability- with its key dimensions- is shown in Figure 1 below.

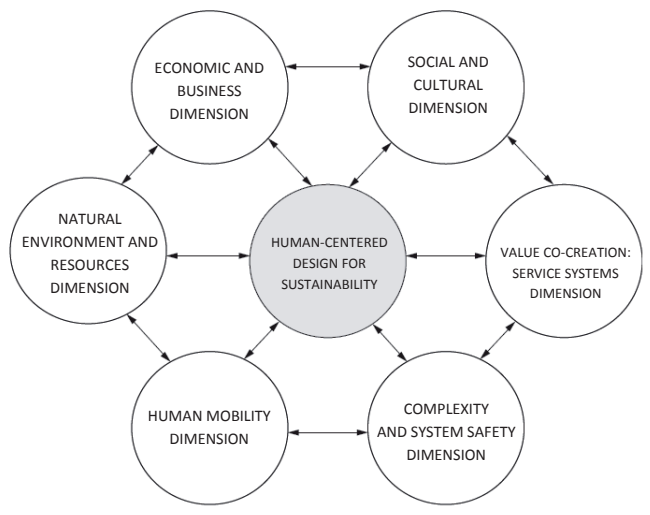

Fig. 1: A generic framework of the human-centered dimensions for design for sustainability.

\section{Human-Centered Design and Sustainability 4.1 The quest for sustainability}

As discussed by Adams (2000), sustainability should be the basis of a new understanding of 
human aspiration and achievement, and the relevant metric of sustainability should be "the production of human wellbeing". Current HFE knowledge can facilitate and support the realization of a human-centered approach to address a broad set of sustainability considerations.

The World Summit on Social Development (2005), identified three sustainable development goals in terms of economic development (sustainable economy), environmental protection (sustainable environment), and social development (sustainable society). In the framework proposed in this paper, we consider the above goals in the context of three sub-systems described in terms of several human factors sustainability dimensions. Such dimensions can be aggregated along the sustainability considerations related to sustainable enterprise, sustainable technology (product and process), and sustainable society (Fiskel 2003). A sustainable enterprise can be defined as one that continues to grow and adapt in order to meet the needs and expectations of its shareholders and stakeholders. The sustainable technology (product or service) is one that continues to meet the needs of its producers, distributors, and customers by saving resources, increasing efficiency, and designing-out errors, risks and safety deficiencies. A sustainable society is one that continues to satisfy the current needs of its population without compromising quality of life for future generations (Fiskel, 2003).

\subsection{Taxonomy of human-centered system sustainability considerations}

In order to conceptualize the human-centered system sustainability, a taxonomy of dimensions reflecting the three sets of sustainability considerations is used, namely: 1) a human-entered society system sustainability consideration (S), 2) enterprise system sustainability considerations $(E)$, and 3) technology system sustainability considerations $(T)$. A conceptual framework of the human-centered systems sustainability considerations illustrated in Figure 2 below.

\subsection{Generic human-centered system sustainability indicator}

The above discussed conceptual framework can be used to define a generic human-centered system sustainability indicator (HCSI), based on three main subsystems (see Figure 2). The value of each subsystem can be calculated using the weighted average method for a particular set of individual sustainability components (i.e.

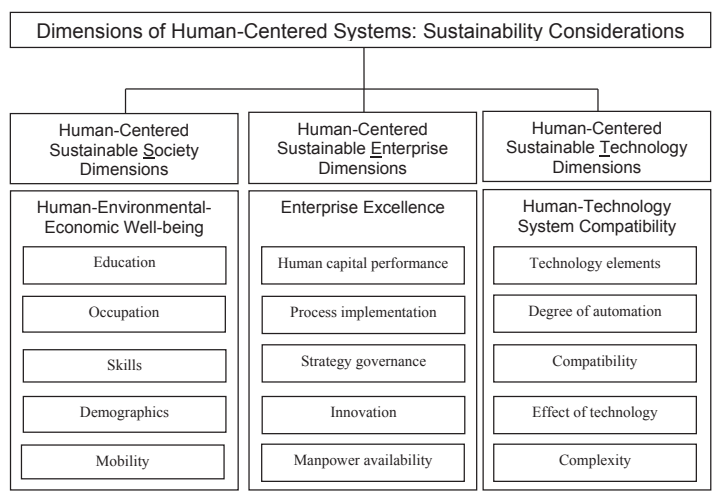

Fig. 2: A conceptual framework of the human-centered system sustainability dimensions.

sustainability efforts and influencing factors) using equation 1 shown below:

$$
H C S I=W_{S} S_{I}+W_{E} E_{I}+W_{T} T_{I}
$$

where: $0 \leq\left(W_{S}, W_{E}, W_{T}\right) \leq 1$

Si: Society related human-centered system sustainability indicator

El: Enterprise (business) related human-centered system sustainability indicator

Ti: Technology related human-centered system sustainability indicator.

The calculation of each human-centered system sustainability indicator is driven by the average value of the specific sustainability components of each of the main sets (see Figure 2). In generic terms, the sustainability indicator values can be calculated using equations 2, 3 and 4, at the society, enterprise and technology levels, respectively;

$$
\begin{aligned}
& S_{I}=\frac{\sum_{i=0}^{n} s_{i}}{n} \\
& E_{I}=\frac{\sum_{i=0}^{n} e_{i}}{n} \\
& T_{I}=\frac{\sum_{i=0}^{n} t_{i}}{n}
\end{aligned}
$$

For example, the society related sustainability indicator (SI) can be calculated based on the weighted average of the values for each of the elements reflecting societal dimensions such as the level of HFE education, occupation, skills, 
demographics, and mobility of skills, where each element is assigned a value between 0 and 1 : $\left[0 \leq S_{1}, S_{2}, S_{3}, \ldots, S_{n} \leq 1\right]$. Similarly, the enterprise related sustainability indicator (EI) can be quantified by business dimensions such as human capital performance, process implementation, business strategy, innovation, and manpower availability, where each element is assigned a value between 0 and 1 : $\left[0 \leq \mathrm{e}_{1}, \mathrm{e}_{2}, \mathrm{e}_{3}, \ldots, \mathrm{e}_{n} \leq 1\right]$. Finally, the technology related sustainability indicator ( $\mathrm{TI}$ ) can be described and measured by such dimensions as technology complexity, degree of automation, compatibility and effect of technology on human-system performance, and environmental impact, where each element is assigned a value between 0 and 1 : $\left[0 \leq \mathrm{t}_{1}, \mathrm{t}_{2}, \mathrm{t}_{3}, \ldots, \mathrm{t}_{\mathrm{n}} \leq 1\right]$.

\subsection{Human-Centered Sustainable Societal Subsystem}

The assessment of indicators for the societyrelated sustainability can be based on the society sustainability index (SSI) developed by the Sustainable Society Foundation (2015). The society sustainability index involves consideration of human, environmental and economic wellbeing. The SSI includes a total of 21 indicators, classified into 7 categories and 3 wellbeing dimensions. Application of HFE knowledge can provide a structured approach to measuring various societal indicators of sustainability, such as quality of life based on product (or service), availability, and user satisfaction; risk perception and community trust; illness or disease avoidance; safety improvement with lost-time due to injury and number of accidents; and measurement of economic indicators of the cost of nutrition needed to maintain optimal cognitive and physical job demands and a healthy lifestyle. For example, the HFE discipline can support measuring societal sustainable development efforts with respect to basic operations, reliability, and performance as originally proposed Chapanis (1995). This includes:

A. Overall operational objectives: reduce errors, increase safety, and improve performance.

B. Objectives related to reliability, maintainability, and availability of human resources: increase reliability, reduction of personnel requirements, training requirements.

C. Objectives affecting society in general (users and operators): improve the working environment, reduce fatigue and physical stress, ease of use, user acceptance, and aesthetic appearance.

D. Other objectives: reduce losses of time and equipment, and increase economy of production.

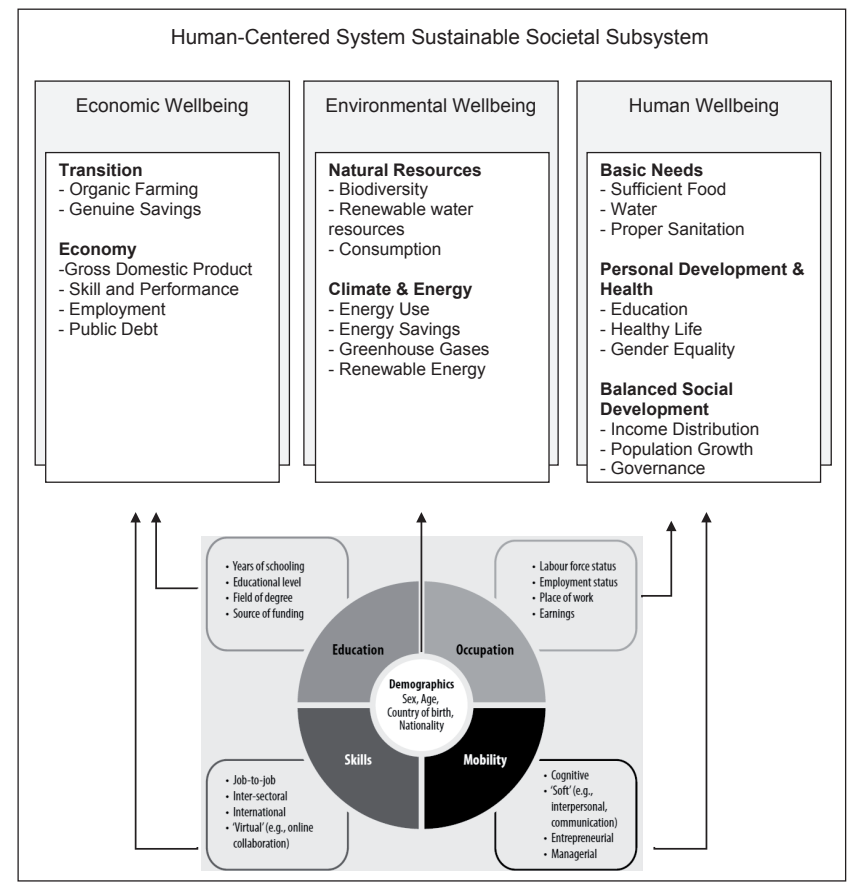

Fig. 3: Conceptualization of the society sustainability subsystem (modified from original by SSI, 2015; and Global Innovation Index, 2014). 


\subsection{Human-Centered Sustainable Enterprise Subsystem (E)}

Many organizations continually seek to develop dynamic and strategic resilience with robust, sustainable, and affordable business models. Enterprise sustainability thrives on business dynamics and the ability to re-invent business models, improve decision-making processes, and develop strategies to anticipate and adjust to dynamic market changes and demands. HFE can provide the medium and platform on which to drive assessment of performance of the enterprise based on human reliability analysis, data-analytics, and improvement of the human decision-making process.

The assessment of sustainability components for the enterprise-related sustainability indicator (EI) can be based on a useful framework (see Figure 4) for Sustainable Enterprise Excellence (SEE), previously developed by Edgeman (2013). SEE is based on the reliable assessment of enterprise performance and best practices for enterprise innovation. In addition to identifying key business criteria for sustainability, the model builds on the performance maturity assessment and compatibility measures. In this model, a more responsive decision-making process leads to sustainable and innovative enterprise strategies, where innovation can be considered a direct measure of enterprise sustainability and ability to overcome business challenges. From this perspective, enterprise intelligence, which is based on human performance reliability and improved technology compatibility, provides enterprises with the advantage of measurable sustainable innovation.

Figure 4 illustrates an exemplary SEE framework (Edgeman 2013), which aligns with HFE in the following significant dimensions for enterprise sustainability and innovation:

$\checkmark$ Human capital performance: innovation capacity and performance, manpower general competence and performance agility, strategic and tactical continuous improvement, and performance development and intelligence.

$\checkmark$ Process implementation and execution: enterprise innovation, resilience and robustness, and innovation for sustainability (innovation index).

$\checkmark$ Enterprise strategy governance dimension: policy and responsibility, robustness, decision-making process, agility, organizational design, and change.

$\checkmark$ Manpower performance: manpower and human capital return on investment, manpower total ownership cost, human capital investment, and investment on innovation.

$\checkmark$ Innovation performance: Innovation for resilience and robustness, and business model and organization design innovation.

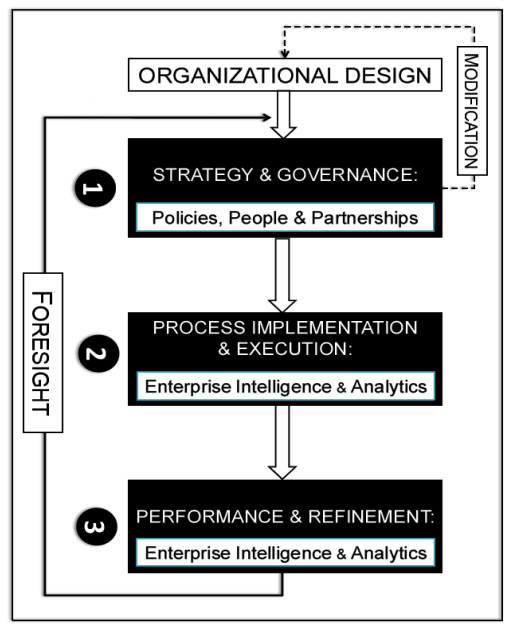

Fig. 4: Example of the sustainable enterprise excellence framework (source: Edgeman, 2013).

In addition, the general classification scheme for HFE can also be used to develop an enterprise related human-centered sustainability indicator by adapting in the following key components:

$\checkmark$ Work design and organization: total system design and evaluation, hours of work, job attitudes and job satisfaction, job design, payment systems, selection and screening, training, supervision, use of support, and technology selection.

$\checkmark$ Workplace and equipment design: general workplace design and buildings, workstation design, and equipment design.

$\checkmark$ Physical environment: level of desired illumination, noise, vibration, whole body movement, climate, altitude, depth, space, and other environmental issues.

\subsection{Human-Centered Sustainable Technology Subsystem (T)}

Technology represents an entire system of people and organizations, knowledge, processes, and devices, all of which support creating, developing, implementing, and operating technological artifacts. The development of sustainable technology involves addressing issues related to complexity and human-system compatibility issues. This is provided by the discipline of HFE 
which identifies technological and environmental requirements and affordances, and balances human operator capabilities and limitations, as shown in Figure 5.

The assessment of sustainability component indicators for the technology-related can be based on a holistic approach to assess human-system compatibility in the context of quality of working life and system performance (Karwowski 2006). This approach reflects the nature of complex compatibility relationships with respect to human operator limitations and capacities, technology complexity with respect to products, devices, machines, processes, and computer-based systems, and enterprise environment with respect to business processes and organizational structure. Performance is an outcome of the compatibility between individual characteristics, requirements, and affordances with respect to technology and environment. The negative outcomes can involve both human-related and system/technologyrelated drawbacks and errors, such as loss of productivity, quality degradation, safety risks, injuries, accidents, physical or cognitive stresses, and subjective behavioral outcomes such as task dissatisfaction, occupational stress, or fatigue (Karwowski 2005).

The above represent the main contributing factors related to assessment of the humancentered technology sustainability indicator (TI). The quality of the working environment is affected by 'positive' and 'negative' outcomes of the complex compatibility relationships. Positive outcomes are reflected by increased productivity, improved performance times, and overall product or service quality. Psychological (subjective or desirable) outcomes are those related to perceived job satisfaction, employee well-being, and commitment (Karwowski 2005).

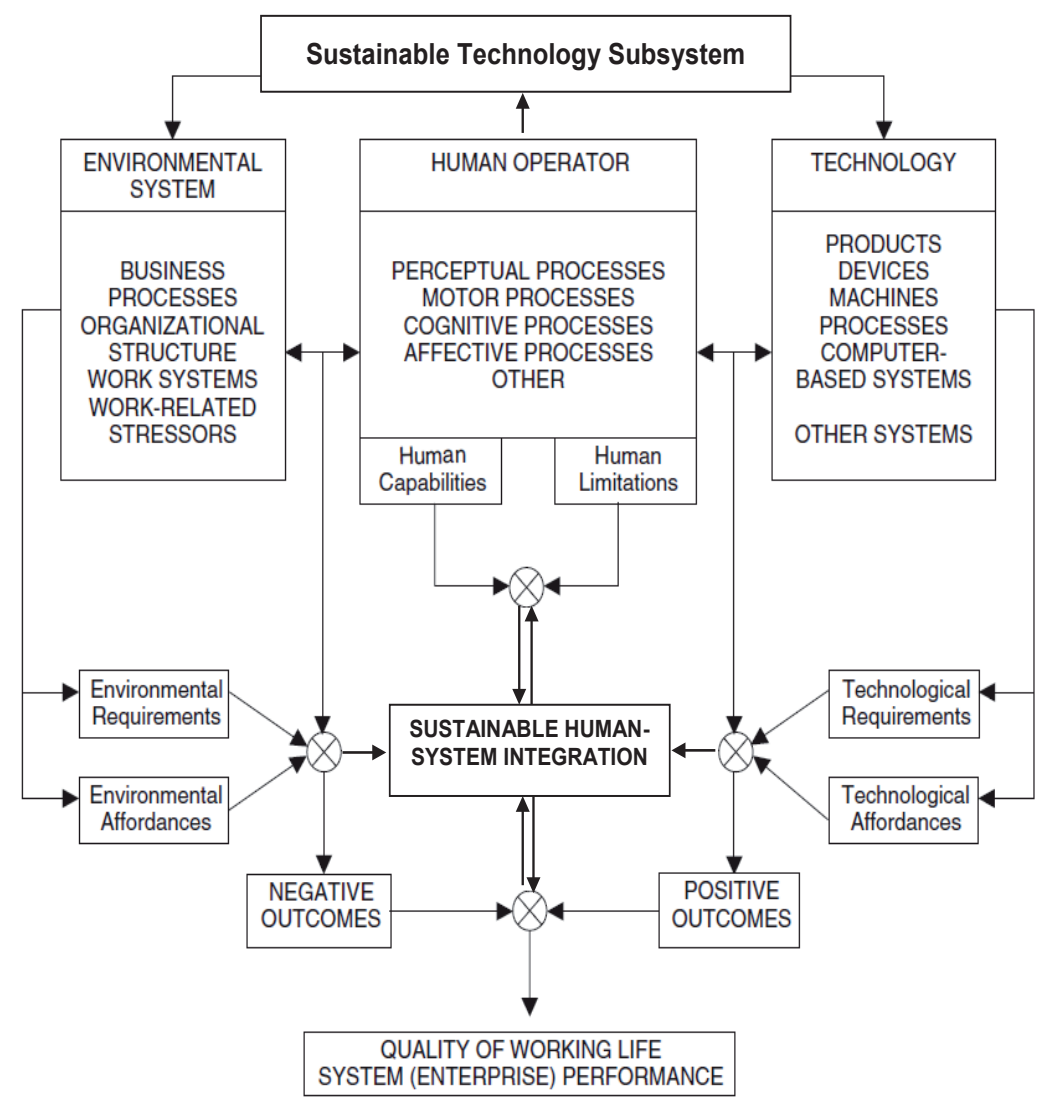

Fig. 5: Sustainable technology in the context of human-system compatibility (modified from original by Karwowski, 2005). 
In addition to the above, the assessment of sustainability components for the technologyrelated sustainability indicator $(\mathrm{TI})$ can also be based on the generic taxonomy of HFE with respect to technology elements, originally proposed by Meister (1999). Such a taxonomy can be used to support the development of sustainable and reliable technology, and assess the technology sustainability sub-index based on the following factors:

- Technology elements: components and tools, equipment, and systems.

-Degree of automation: mechanization, computerization, and artificial intelligence.

- Compatibility: dimensions, attributes, and variables.

- Effect of technology on the human: changes in human role and behavior.

- Organization-technology complexity: definition of organizational variables.

It is noteworthy that ineffective communication and interaction between key technological systems and users has been stated as a major contributing cause of many accidents in different safety-critical systems. For example, the BP Deepwater Horizon (DWH) accident, which occurred in April 2010 in the Gulf of Mexico, was a large-scale accident in the oil and gas industry caused by the failure of industry management to address human-system (technological) and human-human (enterprise) communications- in particular, ineffective communication between BP and its contractors (Chief Counsel's Report, 2011). According to Karwowski (2006), the lack of a universal matrix to quantify human-system-technology compatibility is an important obstacle in the achievement of full sustainability, and is considered a critical aspect of managing safety and risks of occupational accidents. One of the plausible measures of sustainable organizational development is the rate of occupational accidents reported by various countries (see Figure 6).

One of the major challenges to any sustainability initiative is the cost and time delay resulting from injuries due to human-technology-environment incompatibility. For example, the National Safety Council (see Figure 7) indicated that the total cost of unintentional injuries in United States in 2012 was $\$ 730.7$ billion, with workplace deaths and injuries accounting for $\$ 176.9$ billion, public related accidents $\$ 112.5$ billion, home related injuries \$204.7 billion, motor vehicle related accidents $\$ 258$ billion, and work/motor vehicle injuries $\$ 21.4$ billion (National Safety Council 2012). Furthermore, the United Nations indicated that the global fatalities from work-related (occupational) incidents and disease was an estimated 2.2 million in the year 2001. According to the International Labor Organization: "in some parts of the world, many workers will probably die for lack of an adequate safety culture." Even though occupational safety continues to improve, the associated costs are still staggering and provide a real challenge for any sustainability initiative.

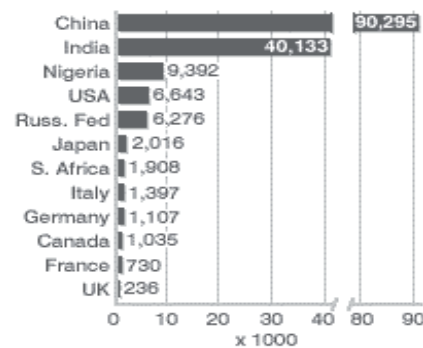

Fig. 6: Estimated fatal workplace accidents in 2001 (source: International Labor Organization Statistics, 2001).

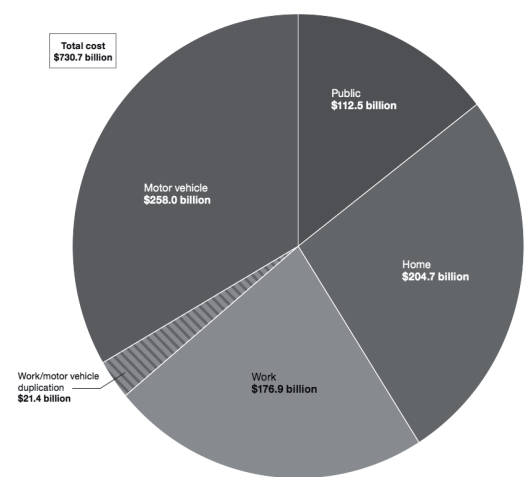

Fig. 7: Cost of unintentional injuries by class in 2010 (source: National Safety Council 2012 Injury Facts).

\section{Sustainability Performance Subsystems}

In general, a useful taxonomy of sustainability performance indicators must include economic, environmental, and societal considerations (Fiskel, 2003). These three subsystems can be used to develop a method for quantifying system sustainability based on the concepts of the information theory (Shannon, 1948), and the compatibility theory (Karwowski, 2005). The plausible architecture of these three sustainability 
subsystems, i.e.: 1) economic subsystem (EC), 2) environmental subsystem (EN), and 3) societal subsystem (SO), and relevant examples of their main sustainability components are described in the next section.

\subsection{Sustainable Economic Subsystem (EC)}

The economic sustainability subsystem include consideration of the following sets of factors: 1) direct factors, such as raw material and labor costs, and capital and operating costs; 2) potentially hidden factors, such as recycling revenue and product disposition cost; 3) contingent factors, such as employee injury cost and customer warranty cost; 4) relationship factors, such as customer retention and business interruption due to stakeholder interventions; and 5) external factors, such as ecosystem productivity loss and resource depletion (Fiskel 2003)

\subsection{Sustainable Environmental Subsystem (EN)}

The environmental (eco) sustainability subsystem include consideration of the following sets of factors: 1) material consumption, such as product and packaging mass, useful product lifetime, hazardous materials used, and eco-efficiency; 2) energy consumption, such as life cycle energy and power use; 3) local impacts, such as product recyclability and runoff to surface water; 4) regional impacts, such as smog creation, acid rain precursors, and biodiversity reduction; and 5) global impacts, such as global warming emissions and ozone depletion (Fiskel 2003).

\subsection{Sustainable Societal Subsystem (SO)}

The societal-sustainability subsystem include consideration of the following sets of factors: 1) quality of life, including product or service availability and employee satisfaction; 2) peace of mind, in terms of perceived risk and community trust; 3) illness and disease reduction, such as illness avoidance and mortality reduction; and 4) safety improvements, in terms of lost-time injuries, number of incidents, health and wellness, nutritional value, and subsistence costs (Fiskel 2003).

\section{Human-Centered Design and Sustainability 6.1. Information-based system component sustainability measure}

The human-centered system sustainability subindices (economics, environmental and societal) can be derived using the formula that reflects the impact of all individual components on each of these sub-indices. The individual sustainability component measure defines the degree to which a specific sustainability criterion has been met. The quantification framework for such an assessment follows the notion of system compatibility theory (Karwowski, 2005) and based on information theory of Shannon (1948).

The unit of measurement for any individual component of the sustainability subsystem is defined based on the analogy to a measure of compatibility (Karwowski 2006) with respect to some optimal, ideal, or desired reference values and criteria, and is expressed in terms of individual subsystem component indicators, i.e. sustainability indicators (Sli). On one hand, such sustainability component indicators can include, for example, the maximum acceptable emission levels of $\mathrm{CO}_{2}$ into the atmosphere, the maximum levels of energy utilization, the maximum levels of urban crime, or the maximum levels of an exposure to specific harmful environmental conditions over time. On the other hand, some of the sustainability component indicators may be reflective of the desirable characteristics, such as exceeding the minimum value of parameters that satisfy the required system sustainability criteria. For example, the can include the ease of use or user acceptance of consumer products, the expected minimum level of food safety, or the expected minimum service quality in health care, education, or other services.

\subsection{Sustainability measurement criteria}

In general, to optimize the effectiveness of sustainability efforts, one can apply one of the two sustainability measurement criteria (SMC-I and SMC-II), which consider the relationship between sustainability requirements $(R)$ and actual values of sustainability attributes (A) related to specific system components for each of the three sustainability subsystems, i.e. economic (EC), environmental (EN), and societal (SO) subsystem.

Sustainability criterion I (SMC-1): This criterion aims to minimize negative and harmful outcomes from a sustainability point of view, including undesirable effects of social, environmental, business, or technological components, parameters, or conditions, over a set of specific sustainability criteria.

Sustainability criterion II (SMCII): This criterion aims 
to maximize the positive influence of sustainable system components, in terms of their desirable features, parameters, or conditions over a set of specific sustainability criteria.

\subsection{Sustainability measurement criterion I (SMC-I)}

This criterion refers to the need to minimize negative effects when a given sustainability requirement (for example, the maximum level of allowable exposure to a given sustainability component), is exceeded, i.e. when the value of a sustainability attribute (A) for a given system component is greater than a specific criterion for sustainability requirement (R). In this case, the sustainability index Slli that ranges from 0 to 1 , can be defined by the ratio: $\mathrm{Ri} / \mathrm{Ai}$, where $\mathrm{Ri}$ is the specific sustainability requirement (for example, the maximum allowable exposure to a harmful agent) for a system component (i), and $A i$ is the actual value of a given sustainability attribute (exposure) for the same system component (i). The value of Slii is expressed by the following equation:

$$
\mathrm{SI}_{\mathrm{I}} \mathrm{i}=\frac{\mathrm{R}_{\mathrm{i}}}{\mathrm{A}_{\mathrm{i}}}
$$

Furthermore, in such a case, the corresponding sustainability risk (SRii), which specifies the risk that sustainability requirements are not met, can be defined as follows:

Sustainability riskı $=-\log _{2}$ [sustainability index]

Sustainability riskı $=-\log _{2}$ [sustainability requirement / sustainability attribute]

Sustainability risk $=-\log _{2} S l_{i}=-\log _{2}\left(R_{i} / A_{i}\right)=\log _{2}$ $\left(\mathrm{A}_{i} / \mathrm{Ri}_{\mathrm{i}}\right.$ [sbits]

where: [sbits] are defined as sustainability bits that measure the risk of not meeting the sustainability goals. It should be noted that when $A_{i}<R_{i}$, the sustainability index Slii can exceed 1, indicating better sustainability performance than expected by some minimum standard of protection against risk.

\subsection{Sustainability measurement criterion II (SMC-II)}

This criterion refers to the need to maximize positive effects in terms of desirable system features when the minimum requirements are not met, i.e. when the value of a sustainability attribute (A) for a given system component is smaller than the value of a specific sustainability requirement (R) for that component (for example, a minimum recommended daily nutrition level). In this case, the sustainability index SIlli, which ranges from 0 to 1 , can be defined by the ratio: $\mathrm{Ai} / \mathrm{Ri}_{\mathrm{i}}$ where $\mathrm{Ai}$ is the actual value of a given sustainability attribute for system component (i), and Ri is the specific sustainability requirement for the same system component (i). The value of Slui is expressed by the following equation:

$$
\mathrm{SI}_{\mathrm{II}} \mathrm{i}=\frac{\mathrm{A}_{\mathrm{i}}}{\mathrm{R}_{\mathrm{i}}}
$$

Furthermore, in such a case, the corresponding sustainability risk (SRi), which specifies the risk that sustainability requirements are not met, can be defined as follows:

Sustainability risk॥ $=-\log _{2}$ [sustainability index]

Sustainability risk $\|=-\log _{2}$ [sustainability attribute / sustainability requirement]

Sustainability risk $\|=-\log _{2} \mathrm{Sli}=-\log _{2}(\mathrm{Ai} / \mathrm{Ri})=$ log2 (Riz/Ai) [sbits]where: [sbits] are defined as sustainability bits that measure the risk of not meeting the sustainability goals. It should be noted that when $A_{i}>R_{i}$, the sustainability index Slıi value exceeds 1 , indicating better sustainability performance than expected by some minimum standard of quality, protection, or human/societal well-being.

\subsection{Sustainability Indices for Economic, Environmental and Societal Subsystems}

In general, the human-centered sustainability sub-index for each of the three subsystems: economic (SI_EC) environmental (SI_EN), and societal (SI_SO) is defined as the average of the sum of all individual component sustainability indices for the respective subsystem, as follows:

$$
\begin{aligned}
& S I \_E C=\frac{\sum_{i=1}^{n} S I_{i}}{n} \\
& S I \_E N=\frac{\sum_{i=1}^{n} S I_{i}}{n} \\
& S I \_S O=\frac{\sum_{i=1}^{n} S I_{i}}{n}
\end{aligned}
$$

where: $[\mathrm{n}]$ is the number of individual components considered in calculating sustainability index for the specific sustainability subsystem. 


\subsection{The Global Sustainability Index}

The global sustainability index (GSI) can be defined as the sum of the three humancentered sustainability measures, i.e. economic, environmental, and societal sub-indices, as follows:

$$
\mathrm{GSI}=\mathrm{SI} E \mathrm{EC}+\mathrm{SI} \mathrm{EN}+\mathrm{SI} \mathrm{SO}
$$

It should be noted that the proposed global index is conceptually somewhat analogous, but not identical in its architecture, to the Global Innovation Index (GII, 2015). The Gll is based on two sub-indices, the innovation input subindex and the innovation output sub-index, and provides a composite indicator (calculated as the weighted average of 81 individual indicators) that ranks countries/economies around the world in terms of their environment for innovation and their innovation outputs.

\section{Discussion}

In general, having a strong infrastructure and appropriate manpower capabilities dictates how nations innovate and develop, and whether they prosper or fade. Contemporary societies have to reuse and recycle, modify and apply best practices, and invest in technology and employees (intellectual capital) in order to accelerate their ability to solve technological, environmental, and/ or social challenges, including, for example, energy demands or famine in Africa.

This paper provides the motivation for developing a practical human-centered system sustainability index. While a large body of knowledge must be integrated towards the development of large-scale sustainable systems, considerable advancements achieved in many smaller (?) fields indicates that adaptation of such knowledge can lead to highly sophisticated, yet widely useable collaborative and user-centered applications that support building a sustainable future at a global level.

Future research efforts will focus on developing parametric architecture for the proposed global human-centered system sustainability index (GSI), and designing a corresponding system for assessing all factors that are components of such an index. It is envisioned that within a year, it will be possible to collect the information needed for calculating the GSI, first in the United States, and then progressively in other countries around the world in the not so distant future.

\section{Conclusions}

This paper proposes a conceptual framework for quantifying human-centered system sustainability based on measures of component measures of sustainability at the levels of society, enterprise, and technology. The discipline and profession of human factors and ergonomics can significantly contribute to building a sustainable future for all citizens. Sustainability promotes the development of innovative, smart, and efficient workplaces, enterprises, and communities. From this perspective, an application of human factors and ergonomics knowledge in the quest for sustainability requires an integration of several disciplines, including HFE, economics, social engineering, environmental science, systems engineering, and above all, application of humancentered approaches and strategies.

Human factors and ergonomics has the unique opportunity to provide a meaningful and practical contribution to this century by helping solve global challenges, including climate change, population malnutrition, effects of armed conflicts, infectious diseases such as Ebola, and energy and water security. The discipline and profession of human factors and ergonomics has also the opportunity to contribute to improving human health, wellbeing, and life expectancy, as well as sustained economic prosperity for all citizens of the world.

\section{References}

[1] Adams, W.M., 2006. The Future of Sustainability Re-thinking Environment and Development in the Twenty-first Century. The World Conservation Union. Report of the IUCN Renowned Thinkers Meeting, 29-31 January 2006

[2] Adams, W. M. and Jeanrenaud, S. J., 2008. Transition to Sustainability: Towards a Humane and Diverse World. Gland, Switzerland: IUCN. 108 pp. ISBN 978-2-8317-1072-3.

[3] Brundtland, B.,H. 1987. Our Common Future, Oxford University Press, Oxford.

[4] Chapanis, A., 1995, Human Factors in System Engineering, Wiley, New York.

[5] Chapanis, A., 1999, The Chapanis Chronicles: 50 Years of Human Factors Research, Education, and Design, Aegean, Santa Barbara, CA

[6] Chief Counsel's Report (2011). Macondo, the Gulf oil disaster, National Commission on the BP Deepwater Horizon Oil Spill and Offshore Drilling, Washington, D.C. 
[7] Edgeman, R., 2013, Sustainable Enterprise Excellence: Towards a framework for holistic data- analytics Corporate Governance - The International Journal of Business in Society, Vol. 13, No. 5, http://www.emeraldinsight.com/products/journals/journals.htm?id=cg Special Issue on Sustainability \& Innovation: Accepted 20 June 2013

[8] EIAC (2000), Ergonomics Abstracts, Ergonomics Information Analysis Centre, School of Manufacturing and Mechanical Engineering, University of Birmingham, Birmingham England.

[9] Fiksel, J., 2003. Designing Resilient, Sustainable Systems. Environ. Sci. Technology 37: 5330-5339.

[10] Gll, 2014, The Global Innovation Index 2014: The Human Factor In innovation, Cornell University, INSEAD, and WIPO: Fontainebleau, Ithaca, and Geneva (ISBN 978-2-9522210-61).

[11] International Labor Organization, website: http://www.ilo. org/global/lang--en/index.htm

[12] Karwowski, W. 2005. Ergonomics and Human Factors: The Paradigms for Science, Engineering, Design, Technology, and Management of Human-Compatible Systems. Ergonomics, 48 (5), $436-463$.

[13] Karwowski, W., 2006, The Discipline of Ergonomics and Human Factors, in: Handbook of Human Factors \& Ergonomics 3rd edition, G. Salvendy, (Ed.), John Wiley, New York, pp. 1-25

[14] Karwowski, W., 2007, Grand Challenges for HFES and Its Place in a Changing World: The Next 50 Years. Presidential Address at the Human Factors Society 50th Annual Meeting, Unpublished PPT presentation, Santa Monica, California, September 2007.

[15] Karwowski, W., 2008, Building Sustainable Human-Centered Systems: A Grand Challenge for the Human Factors and Ergonomics in the Conceptual Age. In: K. Zink (Ed.), Corporate Sustainability as a Challenge for Comprehensive Management; Physica- Verlag: Heilderberg, pp.117-126.

[16] Meister, D., 1999, the History of Human Factors and Ergonomics, Lawrence Erlbaum Associates, London.

[17] Moray, N., 1995, Ergonomics and the Global Problems of the Twenty-First Century. Ergonomics, 38(8), 1691-1707.National Safety Council, Website: http://www.nsc.org

[18] Salvendy, G., Ed., 1997, Handbook of Human Factors and Ergonomics, 2nd ed., Wiley, New York.

[19] Sanders, M. M., and McCormick, E. J., 1993, Human Factors in Engineering and Design, 7th ed., McGraw-Hill, New York.

[20] Society Sustainability Index (SSI), Website: http://www.ssfindex.com

[21] Shannon, C.E., 1948, A mathematical theory of communication. The Bell System Technical Journal, Vol. 27, pp. 379-423, 623-656, July-October, 1948.

[22] Stanton, N., Hedge, A., Brookhuis, K., Salas, E., and Hendrick,
H. W., 2004, Handbook of Human Factors and Ergonomics Methods, CRC Press, Boca Raton, FL.

[23] The Global Innovation Index 2014: The Human Factor in Innovation, 2015, Dutta, S., Lanvin, B. and Wunsch-Vincent, S. Eds., Cornell University, INSEAD, and WIPO, Fontainebleau, Ithaca, and Geneva.

[24] United Nations General Assembly, 1987. Report of the World Commission on Environment and Development: Our Common Future. Annex to document A/42/427 - Development and International Co-operation: Environment, New York.

[25] United Nations General Assembly, 2005. World Summit Outcome, Resolution A/60/1, adopted by the General Assembly on 15 September 2005.

[26] United Nations, 2012. Sustainable Development Conference, Rio de Janeiro, Brazil, on June 20-22, 2012

[27] Vicente, K. J., 2004. The Human Factor, Routledge, New York.

[28] Wilson, J. R., and Corlett, E. N., Eds., 1995, Evaluation of Human Work: A Practical Ergonomics Methodology, 2nd ed., Taylor \& Francis, London.

[29] World Commission on Environment and Development, 1987. Our Common Future, Oxford University Press, Oxford, United Kingdom.

\section{Biographical notes}

Waldemar Karwowski, (M'90) received the M.Sc. degree in production engineering and management from the University of Technology of Wroclaw, Wroclaw, Poland, in 1978, the Ph.D. degree in industrial engineering from Texas Tech University, Lubbock, TX, USA, in 1982, and the D.Sc. degree in management science from ORGMASZ, Warsaw, Poland, in 2004. He is currently a Professor and Chairman of the Department of Industrial Engineering and Management Systems, and Executive Director of the Institute for Advanced Systems Engineering, University of Central Florida, Orlando, FL, USA. His research interests include human systems integration, human factors, safety, neuroergonomics, and applications of soft computing and nonlinear dynamics to modeling of humanmachine systems.

Tareq Ahram, received the Master of Science degree in industrial engineering from the University of Central Florida (UCF), Orlando, FL, USA, and the Master of Science degree in engineering management, and Ph.D. degree in industrial engineering from UCF, in 2004 and 2008, respectively, with specialization in human systems integration and large-scale information retrieval systems optimization (search algorithms). He is currently the lead scientist with the Institute for Advanced Systems Engineering, UCF. 